\title{
Paris, Climate Change, and Sustainable Development
}

\section{Francesco Sindico}

Reader in International Environmental Law, University of Strathclyde Law School; Director of the Strathclyde Centre for Environmental Law and Governance Email: francesco.sindico@strath.ac.uk

\begin{abstract}
The Paris Agreement marks a significant moment in international climate law and policy. It represents a confirmation that the international community will continue to approach climate change multilaterally. However, climate change is not the only topic on countries' agendas. The year 2015 will also be remembered for the adoption of the so-called Sustainable Development Goals (SDGs). This paper critically assesses the extent to which the Paris Outcome incorporates the SDGs or sustainable development concerns. It concludes that a close scrutiny of the Paris COP Decision and Agreement reveals both direct and indirect references to the SDGs and sustainable development (with the former being fewer in number than the latter). The close relationship between international climate law and the SDGs highlights the need to integrate the SDGs into the implementation of the Paris Agreement.
\end{abstract}

\section{Keywords}

Paris Agreement; Sustainable Development Goals; mutual supportiveness; loss and damage; cooperative mechanisms.

\section{Introduction}

The year 2015 has been extremely important for both climate change and sustainable development. In September, the UN General Assembly adopted the Sustainable Development Goals after two years of negotiations, ${ }^{1}$ launched after the Rio+20 Conference in $2012 .^{2}$ In December, the parties to the UNFCCC adopted the Paris Outcome, which consists of the Paris Agreement and the accompanying COP Decision. ${ }^{3}$ This was the culmination of the work of the ADP, launched at the $2011 \mathrm{COP}{ }^{4}$

This paper focuses on the results of the ADP negotiations and assesses the extent to which the Paris Outcome reflects an alignment with the SDGs. The paper concludes that there are three main kinds of reference or approach to sustainable development in the Paris Outcome. First, the concept of sustainable development per se is quite prominent

\footnotetext{
1 'Transforming Our World: The 2030 Agenda for Sustainable Development', (2015) A/RES/70/1, United Nations Sustainable Development Knowledge Platform,

$<$ https://sustainabledevelopment.un.org/post2015/transformingourworld/publication $>$.

2 'The Future We Want: Outcome Document Adopted at Rio +20', (2012) A/RES/66/288, United Nations Conference on Sustainable Development, $<$ http://daccess-ddsny.un.org/doc/UNDOC/GEN/N11/476/10/PDF/N1147610.pdf?OpenElement>.

${ }^{3}$ UNFCCC, Decision 1/CP.21, 'Adoption of the Paris Agreement', FCCC/CP/2015/10/Add.1.

${ }^{4}$ UNFCCC, Decision 1/CP.17, 'Establishment of an Ad Hoc Working Group on the Durban Platform for Enhanced Action', FCCC /CP/2011/9/Add.1.
} 
and is presented as the context in which climate change action and support should operate. Second, sustainability considerations are present throughout the Paris Outcome in relation to measures aimed at mitigating and adapting to climate change. This is particularly relevant for the future of market-based measures. Thirdly, the paper touches briefly on some further linkages between the content of the SDGs and the Paris Agreement, some of which, like adaptation and loss and damage, can be found in the operative part of the Agreement, and others, like the importance of oceans, ecosystems, and food security, in the preamble to the Paris Agreement.

\section{Direct References to Sustainable Development in the Paris Outcome}

The Paris Agreement does not make any explicit reference to the SDGs. But then it does not refer to any other international legal instrument. While it could have been interesting to see the Agreement reciprocate the reference that the SDGs make to the UNFCCC, ${ }^{5}$ the absence of such a reference does not mean that the SDGs, and what they embody, are not relevant in the Paris Outcome. In fact, if one considers the Outcome as a whole, the conclusion changes. The preamble to the COP Decision does make explicit reference to "Transforming our world: The 2030 Agenda for Sustainable Development". In particular, it applauds its specific climate change goal, SDG 13.

The Paris Agreement itself, although lacking a direct reference to the SDGs, refers to sustainable development in a very interesting way. The preamble emphasizes "the intrinsic relationship that climate change actions, responses and impacts have with equitable access to sustainable development and eradication of poverty". But where it gets really interesting is when articles 2 and 4 are read together. Article 2 provides the goal of the Paris Agreement and article 4 expands on this goal, providing guidance to the parties as to what they need to do to meet the goal. Article 2 maintains that: "This Agreement, in enhancing the implementation of the Convention, including its objective, aims to strengthen the global response to the threat of climate change, in the context of sustainable development and efforts to eradicate poverty." 6

Sustainable development and poverty eradication are the overarching goals of the SDGs. The Paris Agreement might as well have said "in the context of the SDGs". Second, the parties agreed that the goal of the Agreement must be considered "in the context" of sustainable development. This is confirmed in article 4:

In order to achieve the long-term temperature goal set out in Article 2, Parties aim to reach global peaking of greenhouse gas emissions as soon as possible, recognizing that peaking will take longer for developing country Parties, and to undertake rapid reductions thereafter in accordance with best available science, so as to achieve a balance between anthropogenic emissions by sources and removals by sinks of greenhouse gases in the second half of this century, on the basis of equity, and in the context of sustainable development and efforts to eradicate poverty. ${ }^{7}$

\footnotetext{
5 'Acknowledging that the United Nations Framework Convention on Climate Change is the primary international, intergovernmental forum for negotiating the global response to climate change.' SDG 13, footnote.

${ }^{6}$ Paris Agreement, art. 2.1.

${ }^{7}$ Ibid., art. 4.1 .
} 
Two observations need to be made at this point. If we agree that sustainable development and poverty eradication are central to the SDGs, and also that sustainable development provides the context in which the Paris Agreement operates, it is critical that the implementation of the Agreement operates in the context of the SDGs. This is where article 4.2 becomes relevant. It reads as follows:

Each Party shall prepare, communicate and maintain successive nationally determined contributions that it intends to achieve. Parties shall pursue domestic mitigation measures with the aim of achieving the objectives of such contributions.

Parties did not add the wording "in the context of sustainable development and poverty eradication", but the point should now be clear that this is implied. Article 4.2, with its clear and mandatory language, imposes a legally binding obligation upon parties. ${ }^{8}$ Such an obligation needs to be consistent with the SDGs. Thus, when developing NDCs and adopting domestic measures to implement them, countries must take account of how they relate to the SDGs. More than that, countries will have to start implementing SDGs in the near future by "pursuing domestic measures". Parties should be aware of this twofold obligation incumbent upon them, and that they take the necessary policy actions to ensure that their domestic implementation of the Paris Agreement and of the SDGs happens in a mutually supportive way and does not push in different directions.

\section{Sustainable Development Considerations in the Paris Outcome}

The second category of references to sustainable development in the Paris Agreement highlight the need to safeguard sustainability in the action that countries take to further mitigate or adapt to climate change. This debate has been present from the very early days of the Kyoto Protocol negotiations, and in particular in the development of the Clean Development Mechanism. Praised by some as a win-win solution to promote cost-efficient emission reductions and sustainable development in developing countries, ${ }^{9}$ others have criticized it as a way for developed countries to escape their moral and historical responsibilities. ${ }^{10}$ Critics of the CDM, and of market-based measures more generally, have argued that developed countries have been the ones responsible for climate change historically, and should take the lead domestically in reducing emissions. Those who advocate in favour of carbon markets maintain that what the planet needs is fewer emissions, and that if this can be achieved in a more costeffective manner in a specific (developing) country, then it should be permitted. In the middle ground are those, including myself, ${ }^{11}$ who have argued that the issue is not

\footnotetext{
${ }^{8}$ Francesco Sindico, 'Is the Paris Agreement Really Legally Binding?', Strathclyde Centre for Environmental Law and Governance, Working Paper no. 03/2015, at 2.

${ }^{9}$ UNFCCC Secretariat, Benefits of the Clean Development Mechanism (2011); and J. Alexeew et al., 'An analysis of the relationship between the additionality of CDM projects and their contribution to sustainable development', 10(3) International Environmental Agreements: Politics, Law and Economics 233-248 (2010).

${ }^{10}$ See A. Michaelowa and J. Buen, 'The CDM gold rush', in A. Michaelowa (ed.), Carbon markets or climate finance?, Routledge, 2012, 1- 38; S. Böhm and S. Dabhi (eds.), Upsetting the offset: The political economy of carbon markets, Mayflybooks; and B. Haya, Measuring emissions against an alternative future: Fundamental flaws in the structure of the Kyoto Protocol's Clean Development Mechanism, University of California, 2009.

${ }^{11}$ F. Sindico, 'Post 2012 compliance and carbon markets', in J. Brunnée, M. Doelle, and L. Rajamani (eds.), Promoting Compliance in an Evolving Climate Regime, Cambridge University Press, 2012, at 254.
} 
whether action outside Annex I countries should have been permitted, but that clear limits should have been mandated as to how much mitigation effort could be undertaken by developed countries through the CDM. The principle of supplementarity provided for in the text of the Kyoto Protocol was never fleshed out, leaving a wide scope for discretion, with some countries being more responsible than others when it came to using, or abusing, carbon credits.

A second element of contention was whether the CDM and carbon markets in fact promote sustainable development. The decision taken in the Kyoto Protocol regime was to leave the assessment of whether a project delivers sustainable development to the host country. With no universal sustainability standards and with national sovereignty still playing an important role in international relations, this approach appeared to be, if not the best, then the more feasible and plausible. ${ }^{12}$

Against this background, it is no surprise that a most contentious issue in the late hours of the Paris negotiations was whether to include a mitigation instrument that promotes sustainable development through the use of markets. ${ }^{13}$ In the Agreement, the CDM is not mentioned, and the language refers, neutrally, to "a mechanism to contribute to the mitigation of greenhouse gas emissions and support sustainable development". ${ }^{14}$ What was witnessed in the last week of negotiations was a confrontation between those parties who wanted to put the final nail in the coffin of the CDM and those who wanted to bring it back to life. While the text of the Agreement may not reveal what the new mechanism will look like, the COP Decision contains clues that do not leave much room for doubt, suggesting a structure that closely resembles that of the CDM. ${ }^{15}$

Indeed, the CMA is mandated to reflect on good practices in, and issues with, the implementation of the Kyoto Protocol's flexible mechanisms and devise modalities and procedures for the new Paris mechanism. The other elements that the CMA must base its work on in preparation of the modalities and procedures again do not leave room for doubt as to what is being considered - primarily additionality. If one is to have "lessons learned from existing mechanisms", ${ }^{16}$ it could be argued that the sustainable development aspects of the new mechanism should be considered by the CMA.

\section{References to the Content of the SDGs in the Paris Agreement}

A closer look at the Paris Agreement reveals further references to the content of the SDGs. Some can be found in the operative part of the Agreement, others in the preamble. I cannot analyse this relationship in any depth in this paper, but I will briefly map it out and make some general observations.

\subsection{Sustainable Development and SDGs in the Operative Provisions of the Paris Agreement}

\footnotetext{
12 The CDM was criticized to such an extent that a civil society organization, CDM Watch, was established just as for human rights abuses.

${ }^{13}$ Sindico, supra note 8.

${ }^{14}$ Paris Agreement, art. 6.4.

${ }^{15}$ COP Decision, para. 38.

${ }^{16}$ Ibid., para. 37(f).
} 
Provisions on adaptation, forestry, loss and damage, and education all relate to SDG content. First, the Paris Agreement makes a very clear link between adaptation and sustainable development. ${ }^{17}$ Article 7 of the Agreement highlights the fact that climate change adaptation will benefit from natural resources being managed in a sustainable manner. This relationship between climate change and sustainable development allows us to go back to the SDGs and consider which of them encourage countries to better manage their natural resources. One example is SDG 6, which calls on countries to "(Ensure) access to water and sanitation for all". Climate change adaptation underscores the need to link the implementation of the SDGs and the Paris Agreement, especially in light of the crucial role of integrated water management for climate change adaptation. ${ }^{18}$

Second, the Paris Agreement contains a stand-alone provision on sinks and forests, with article 5 providing that "Parties should take action to conserve and enhance, as appropriate, sinks and reservoirs of greenhouse gases as referred to in Article 4, paragraph 1(d), of the Convention, including forests". Leaving aside the debate as to whether forests should be protected through market based measures, ${ }^{19}$ what is clear from article 5 is that sustainable management of forests is crucial. This concern and policy priority is well aligned with SDG 15, and in particular with target 15.2, which reads as follows: "By 2020, promote the implementation of sustainable management of all types of forests, halt deforestation, restore degraded forests and substantially increase afforestation and reforestation globally".

Third, a further area of the Paris Agreement in which sustainable development can play an active, positive role in dealing with climate change is the contentious area of loss and damage - one of the thorniest of issues in the last week of the negotiations. ${ }^{20}$ Article 8 of the Paris Agreement provides:

Parties recognize the importance of averting, minimizing and addressing loss and damage associated with the adverse effects of climate change, including extreme weather events and slow onset events, and the role of sustainable development in reducing the risk of loss and damage.

Negotiations on loss and damage began in $2007^{21}$ and culminated with the creation of the Warsaw International Mechanism for Loss and Damage. ${ }^{22}$ There have always been

${ }^{17}$ Ibid., art. 7.9(e).

18 'Transforming our world', supra note 1 , target 6.5 .

${ }^{19}$ On forests and climate change see Rosemary Lyster, Catherine MacKenzie, and Constance McDermot (eds.), Law, Tropical Forests and Carbon, Cambridge University Press, 2013; Charlotte Streck, et al., Climate Change and Forests: Emerging Policy and Market Opportunities, Brookings Institution, 2008; and Joyeeta Gupta, Nicolien van der Griip, and Onno Kuk, Climate Change, Forests and REDD, Routledge 2012. Key COP Decisions on REDD have been collated by the UNFCCC Secretariat: $<$ http://unfccc.int/files/land_use_and_climate_change/redd/application/pdf/compilation_redd_decision_b ooklet_v1.1.pdf>.

${ }^{20}$ Francesco Sindico, 'A Story of 2.0 Texts and of the Landing of the Paris Agreement', Strathclyde Centre for Environmental Law and Governance, Working Paper no. 3/2015.

${ }^{21}$ The discussion on loss and damage formally started with the 2007 Bali Action Plan and was later embedded in the Cancun Adaptation Framework. However, it could be argued that it has been campaigned for by the Alliance of Small Island States since the early 1990s; see Elisa Calliari, Loss and Damage: A Critical Discourse Analysis, <http://papers.ssrn.com/sol3/papers.cfm?abstract_id=2510785>. 
two approaches to loss and damage. Some countries have pursued a liability and compensation scheme, which would oblige developed countries to contribute to a fund which affected states could access. Another set of countries have supported a system that excludes liability and compensation and focuses on the sharing of good practices in early warning and climate-risk assessment. ${ }^{23}$ No wonder the negotiations on loss and damage have been so heated, considering how far apart these approaches are. The Paris Agreement reflects this tension, and a facilitative and non-confrontational approach has now been established. A disclaimer to the effect that "Article 8 of the Agreement does not involve or provide a basis for any liability or compensation" is placed not in the Agreement but in the COP Decision. ${ }^{24}$

How can sustainable development, and the SDGs in particular, contribute to dealing with loss and damage? A few examples will highlight that a link is indeed present and that the two communities implementing the Paris Agreement and the SDGs need to come together. The first example is SDG 11, which calls for "inclusive, safe, resilient and sustainable" cities. Target 11.5 reads as follows:

By 2030, significantly reduce the number of deaths and the number of people affected and substantially decrease the direct economic losses relative to global gross domestic product caused by disasters, including water-related disasters, with a focus on protecting the poor and people in vulnerable situations. ${ }^{25}$

Given that loss and damage frequently occurs because of sudden "disasters", the link is self-evident. Human settlements need to be more "resilient" if they are to better cope with loss and damage arising from climate change. Furthermore, due to the clear relationship between loss and damage and disaster-risk management, the Sendai Framework for Disaster Risk Reduction is particularly relevant. ${ }^{26}$ Loss and damage and disaster-risk management raise a further complexity in the relationship between the Paris Agreement and the SDGs. The latter will sometimes point directly, but often indirectly, to other international legal instruments, institutions, and governance schemes that need to be considered when implementing the Paris Agreement. In other words, when dealing with the relationship between the Agreement and the SDGs, a much more complex and sophisticated legal and institutional framework, made up of links and regime overlaps, must be considered.

A fourth, and for the purposes of this paper, final area in the Paris Agreement that is closely related to the SDGs is "education". If the outcome of COP 21 has rubberstamped the bottom-up approach to international climate policy ${ }^{27}$ launched back in

${ }^{22}$ UNFCCC, Decision 2/CP.19, 'Warsaw international mechanism for loss and damage associated with climate change impacts', FCCC/CP/2013/10/Add.1.

${ }^{23}$ For a discussion on loss and damage, see M. Burkett, 'Loss and Damage', 4(1-2) Climate Law (2014); Benoit Mayer, 'Whose "Loss and Damage"? Promoting the Agency of Beneficiary States', 4(3-4) Climate Law (2014); and Meinhard Doelle, 'The Birth of the Warsaw Loss and Damage Mechanism', 8(1) Carbon and Climate Law Review (2014).

${ }^{24}$ COP Decision, para. 51.

${ }^{25}$ Emphasis added.

${ }^{26}$ Sendai Framework for Disaster Risk Reduction 2015-2030, United Nations Office for Disaster Risk Reduction (2015).

27 The international climate change legal regime has experienced a move from a top-down system, in which some countries had quantitative emission reduction obligations set as targets, to a bottom-up 
Copenhagen, education and public awareness in article 12 of the Agreement are of crucial importance to raise ambition in the long term. A bottom-up approach depends on domestic implementation. For the latter to be more ambitious, citizens must be more aware of, and better educated about, climate change. Only this will direct domestic politics towards more ambitious climate change plans - and maybe even targets.

Article 12 reads: "Parties shall cooperate in taking measures, as appropriate, to enhance climate change education, training, public awareness, public participation and public access to information, recognizing the importance of these steps with respect to enhancing actions under this Agreement."

Among the SDGs, SDG 4 is arguably the education goal, and while it aims primarily to secure primary and secondary education for all, the implementation of target 4.7 could have positive climate change implications:

By 2030, ensure that all learners acquire the knowledge and skills needed to promote sustainable development, including, among others, through education for sustainable development and sustainable lifestyles, human rights, gender equality, promotion of a culture of peace and non-violence, global citizenship and appreciation of cultural diversity and of culture's contribution to sustainable development.

In conclusion, the Paris Agreement's provisions on adaptation, forests, disaster prevention and management (as a way to deal with loss and damage), and education all point to the content of the SDGs. Further references are present in the preamble, which we will now consider briefly.

\subsection{Sustainable Development and SDGs in the Preamble to the Paris Agreement}

Whether an issue ends up in the operative part of a treaty or in the preamble does matter from a legal perspective. ${ }^{28}$ In principle, if it can be found in a treaty provision, it can lead to legally binding obligations, but this depends also on the language used in the provision in question. ${ }^{29}$ If an issue is present only in the preamble of a treaty, any related commitment will usually be considered not to be legally binding, but it can be relevant for interpretation purposes. ${ }^{30}$ It is not surprising, then, that delegations and NGOs that fought hard in the negotiations to position their areas of interest in the operative part of the Paris Agreement were disappointed to see them slip into the preamble. These areas include food security, jobs, human rights, health, rights of

approach in which all countries are asked to pledge what they can contribute in terms of climate change mitigation. This change started with the Copenhagen Accord, pursuant to which most UNFCCC countries submitted their pledges. These then became INDCs in the framework of the ADP negotiations, and have now been enshrined in NDCs as part of the Paris Agreement. See Daniel Bodansky, 'A Tale of Two Architectures: The Once and Future UN Climate Change Regime', 2011,

$<$ http://papers.ssrn.com/sol3/papers.cfm?abstract_id=1773865>; and Francesco Sindico, 'The Copenhagen Accord and the future of the international climate change regime', 1(1) Revista Catalana de Dret Ambiental (2010).

${ }^{28}$ On the relevance of preambles in treaties, see Anthony Aust, Modern Treaty Law and Practice, 3rd ed., Cambridge University Press, 2013.

${ }^{29}$ See Daniel Bodansky, 'Legally binding versus non-legally binding instruments', 2015, $<$ http://papers.ssrn.com/sol3/papers.cfm?abstract_id=2649630 $>$.

${ }^{30}$ This was the case in the famous Shrimp/Turtle case before the WTO's Appellate Body. 
indigenous peoples, migrants, children, people with disabilities, gender, oceans, sustainable lifestyles, and sustainable patterns of production and consumption. Forests, education, and sustainable management of natural systems are mentioned in the preamble but also have a place in the operative part of the Agreement, as noted.

The SDGs directly or indirectly address most of the issues covered in the preamble to the Paris Agreement. Food security is dealt with in SDG 2. Target 2.4 provides a link between sustainable food production, resilient agricultural practices, and climate change. ${ }^{31}$ SDG 8 refers to "full and productive employment", making a link with jobs in the preamble to the Agreement. Health is present in SDG 3. SDG 5 is about gender equality and provides a bridge to the gender reference in the Agreement's preamble. Oceans are in SDG 14, which includes a reference in the targets to ocean acidification. ${ }^{32}$ Sustainable lifestyles and sustainable patterns of production and consumption are the subject matter of SDG $12 .{ }^{33}$ Human rights, indigenous peoples' rights, children, people with disabilities, migrants, all are present in several SDGs and were supported by a coalition of countries led by Mexico and by vast swaths of civil society. The "Friends of the Principles" pushed for acknowledgment of the above groups of people and their rights to be present in the operative part of the Agreement.

In sum, the content of the SDGs can be found in the operative provisions of the Paris Agreement as well as its preamble. The combination of clear SDG language with references in the operative part of the Agreement provides the international community with a strong mandate in the fields of adaptation, forests, disaster prevention and management, and education. For this mandate to be successful an integrated approach to the implementation of the Paris Agreement and the SDGs needs to take place.

\section{Conclusion}

This paper has mapped the presence of sustainable development and the SDGs in the Paris Agreement. It has done so by considering the Agreement's direct references to the SDGs and sustainable development, as well as its indirect references to the content of the SDGs. This review reveals that there are three discrete relationships between sustainable development and climate change. The first one is illustrated by those provisions that call for the Agreement to be implemented "in the context" of sustainable development. The second takes us to those areas of the Paris Agreement that require parties to consider sustainability in the context of the re-emergence of the use of voluntary carbon markets. The last one highlights references to the content of the SDGs,

\footnotetext{
31 'Transforming our world', supra note 1, target 2.4: "By 2030, ensure sustainable food production systems and implement resilient agricultural practices that increase productivity and production, that help maintain ecosystems, that strengthen capacity for adaptation to climate change, extreme weather, drought, flooding and other disasters and that progressively improve land and soil quality."

${ }^{32}$ Ibid., target 14.3.

${ }^{33}$ There was an interesting link between an earlier draft of the COP Decision and the need to change behaviour in large transnational companies as a means to promote private sustainable-production strategies (ibid, target 12.6: "Encourage companies, especially large and transnational companies, to adopt sustainable practices and to integrate sustainability information into their reporting cycle"). Two days before the adoption of the Paris Agreement, the COP Decision still urged "Parties to reduce international support for high-emission investments" (Draft Paris Outcome, Proposal by the President, version 2 of 10 December 2015 at 21:00, on file with author, para. 62).
} 
some of which are present in the operative part of the Agreement while others are only present in the preamble.

A cursory overview of the outcome of COP 21 highlights that, in order to fully appreciate the Paris Agreement, it needs to be understood in the context of sustainable development and the SDGs. For the Agreement to be properly implemented, parties will need to develop a common policy pathway for their efforts on climate change and sustainable development. The Paris Agreement and the SDGs must walk hand-in-hand and support one another. ${ }^{34}$

\footnotetext{
${ }^{34}$ The author attended the last days of COP 21 as an observer. He would like to thank Ms Nicola Crook
} for her research assistance in the preparation of this article. 